\title{
Dinâmica subnacional e lógica centro-periferia: os impactos do Mercosul na economia política dos estados de Pernambuco, Bahia, São Paulo e Rio Grande do Sul
}

\author{
Subnational Dynamics vs. Center-Periphery Logic: The Impact \\ of Mercosur on the Political Economy of Pernambuco, Bahia, \\ São Paulo and Rio Grande do Sul.
}

MARCELO DE A. MEDEIROS*

Rev. Bras. Polít. Int. 49 (1): 43-67 [2006]

En vérité l'Amérique latine n'est une, avec une netteté aveuglante, que vu du dehors... Elle est une par contraste, par opposition, prise dans sa masse continentale, mais à condition d'opposer celle-ci aux autres cotinents, sans que cela l'empêche jamais, d'être profondément divisée.

(Fernand Braudel $)^{1}$

\section{Introdução}

As articulações entre atores políticos e agentes econômicos se dão, no mais das vezes, em função de seus respectivos interesses, mas também em conseqüência de arranjos que se constituem em relação a hierarquias de poder ${ }^{2}$. O lugar do Nordeste na Federação Brasileira repercute direta ou indiretamente em sua capacidade de influenciar o processo integracionista do Mercado Comum do Sul (Mercosul). A definição da matriz de desenvolvimento nacional estando calcada precipuamente em função da centralidade político-econômica do eixo sudeste-sul marginaliza a ação dos entes federativos sententrionais.

\footnotetext{
* Professor do Departamento de Ciência Política da Universiade Federal de Pernambuco (UFPE) e doutor em Ciência Política pela Universidade de Grénoble, França (mam14@uol.com.br).

1 BRAUDEL, Fernand, “Y-a-t-il une Amérique latine?”, Cahiers des Annales, n 4, Paris, 1949.

$2 \mathrm{O}$ presente trabalho resulta de pesquisa desenvolvida com financiamento do CNPq. Ele teve a colaboração estreita do Programa Institucional de Bolsas de Iniciação Científica - PIBIC/UFPE, efetuada pela graduanda em economia Amanda Aires, que fez a pesquisa de campo e contribuiu com a versão preliminar do presente texto. Essa primeira versão foi apresentada na First Global International Conference of the World International Studies Committee - Istambul - August 24-27 - 2005.
} 
Neste texto se procura associar os estudos teóricos relacionados à temática centro-periferia, multi-level governance, federalismo cooperativo e positive and negative integration à realidade empírica das unidades subnacionais no seio do Mercosul. São ainda efetuadas pesquisas de campo junto a atores políticos e representaçôes de agentes econômicos a fim de privilegiar fontes primárias de informação e desta forma analisar comparativamente os impactos do Mercado Comum do Sul na economia política dos estados de Pernambuco, Bahia, São Paulo e Rio Grande do Sul, assim como em suas respectivas capitais.

\section{A Cepal e a dialética centro-perifería}

Qualquer trabalho de investigação sobre a gênese da economia política latino-americana ou brasileira deve, forçosamente, passar pelo pensamento da Comissão Econômica para a América Latina (Cepal). Afinal, esta se constituiu o marco teórico decisivo para a gestão das principais teses sobre desenvolvimento ou subdesenvolvimento periférico que animaram a discussão teórica latinoamericana do pós-guerra ${ }^{3}$.

A Comissão Econômica para a América Latina (Cepal), órgão vinculado à Organização das Nações Unidas (ONU), manifesta-se pela primeira vez com a publicação, em 1950, de El desarrollo Económico de América Latina y Algunos de sus principales problemas, documento de autoria do economista argentino Raúl Prebisch ${ }^{4}$. E sob a forte influência das idéias desse pensador que a Cepal visa a explicar o atraso e a subordinação da América Latina em relação aos países que compóem os centros desenvolvidos, e também a encontrar formas de superar tais problemas.

As idéias de Prebisch e da equipe da Cepal surgem da observação de que o crescimento econômico nos países industrializados não conduz necessariamente ao crescimento nos países mais pobres. $\mathrm{Na}$ verdade, seus estudos sugerem que a atividade econômica nos países mais ricos conduz aos sérios problemas econômicos nos países mais pobres. Tal possibilidade não é predita pela teoria neoclássica, que tem suposto que o crescimento econômico é benéfico a todos, mesmo que os ganhos não sejam sempre igualmente compartilhados. A emersão de uma alternativa para explicar o estado retardatário e dependente em que se encontram os países da América Latina se torna um marco teórico no pensamento econômico. Como elucida Emir Sader:

\footnotetext{
${ }^{3}$ MANTEGA, Guido, A Economia Política Brasileira, Polis/Vozes, 1987, 4ª edição, p. 34.

${ }^{4}$ Secretário-geral, em 1949, da Comissão Econômica para América Latina (Cepal), assumiu na década de 1960 a Comissão das Naçōes Unidas sobre Comércio e Desenvolvimento (Unctad - United Nations Conference on Trade and Development). Influenciou as políticas econômicas implementadas pela Argentina ao longo de todo século XX, em princípio como secretário de finanças e mais tarde como presidente do Banco Central argentino.
} 
O pensamento social latino-americano é responsável por alguns dos maiores avanços teóricos da segunda metade do século XX. A crítica da teoria do comércio internacional - feita pela Cepal e, em particular, por seu fundador, Raul Prebisch - desmascarou os argumentos que pretendiam naturalizar, legitimar e perpetuar a divisão entre um centro capitalista industrializado e uma periferia primário-exportadora. A denúncia do intercâmbio desigual esteve na base dos processos de industrialização em países da periferia que, mesmo com suas deformações e limitaçôes, constituíram uma das grandes novidades positivas do século XX. A industrialização substitutiva de importações foi a estratégia que comandou esse processo ${ }^{5}$.

A explanação inicial de Prebisch para o fenômeno do intercâmbio desigual é muito direta: os países pobres exportam produtos primários para os países ricos que então industrializam (agregando valor) e os vendem de volta para as naçôes desprovidas. $\mathrm{O}$ valor adicionado das mercadorias custa sempre mais do que as matérias-primas usadas para criar aqueles produtos. Conseqüentemente, os países mais pobres nunca estariam ganhando o bastante das suas exportações para compensar o pagamento das importaçôes.

\section{Nas palavras de Celso Furtado ${ }^{6}$,}

(...) o capitalismo industrial levou certos países (os que lideram o processo de industrialização) a especializar-se naquelas atividades em que métodos produtivos mais eficientes penetravam rapidamente, e levou outros a especializar-se em atividades em que essa forma de progresso técnico era insignificante, ou a buscar a via da alienação das reservas de recursos naturais não-reprodutíveis. A "lei das vantagens comparativas", tão bem ilustrada por Ricardo com o caso do comércio anglo-lusitano, proporcionava uma justificação sólida da especialização internacional, mas deixava na sombra tanto a extrema disparidade na difusão do progresso nas técnicas de produção como o fato de que o novo excedente criado na periferia não se conectava com o processo de formação de capital. Esse excedente era principalmente destinado a financiar a difusão, na periferia, dos novos padrôes de consumo que estavam surgindo no centro do sistema econômico mundial em formação. Portanto, as relaçōes entre países cêntricos e periféricos, no quadro do sistema global surgido da divisão internacional do trabalho foram, desde o começo, bem mais complexas do que se depreende da análise econômica convencional.

Para o economista Raul Prebisch, esses países retardatários entram em um estado de dependência em relação aos países do primeiro mundo, convertendo-se apenas em fornecedores de matérias-primas. A esta relação, tal como metrópole-colônia, Prebisch denomina Centro-Periferia. Na qual os países que produzem bens industriais com alto valor agregado se situam no centro das atividades econômicas e políticas e os países que se mantêm na produção de bens primários, com baixo valor contido sobre o preço do produto, se encontram à margem das regiōes centrais e representam a periferia do mercado mundial.

\footnotetext{
5 http://www.alainet.org/active/show_text.php3?key=1061 (acessado em 13.8.2004).

6 http://www.academia.org.br/imortais/cads/11/celso2.htm (acessado em 7.4.2005).
} 
Essa nova dialética forjada pela Cepal, através do seu secretário-geral, contesta a Teoria Clássica do Comércio Internacional, pois argumenta que a especialização dos países em alguns produtos tendo em vista suas vocações naturais, as chamadas vantagens comparativas, longe de diminuir, acentua ainda mais as já consideráveis diferenças entre os países que compõem o Centro e os que estão associados à periferia, pois conforme a Comissão, o aumento da renda emanado da industrialização dos Centros não resulta em acréscimos sobre a demanda dos bens primários ${ }^{7}$, mas sim sobre aquela voltada para os bens produzidos pelo Centro, dilatando, assim, as divergências.Como delineado nos dois trabalhos angulares do pensamento da Cepal (El desarrollo Económico de la America Latina y Algunos de sus Principales Problemas e do Estudio Económico de America Latina, de 1951), o centro desenvolvido não estaria transferindo os benefícios de seus aumentos de produtividade para a periferia atrasada, mas ao contrário, estaria se apropriando dos modestos incrementos de produtividade obtidos por ela. Com isso, Prebisch e a Cepal inauguraram uma nova interpretação do comércio internacional e do subdesenvolvimento. ${ }^{8}$

Tendo em vista os problemas latino-americanos, a Cepal, por meio do pensamento de Prebisch, refuta a hipótese na qual os problemas periféricos seriam resolvidos, como outrora havia enfatizado a Teoria Clássica, por meio dos ajustes de mercado. Observando isso e integrado a uma equipe de pensadores, o argentino deduz um conjunto de reflexōes objetivando atenuar as disparidades existentes. Elas guiariam a economia política de muitos países periféricos, entre eles o Brasil, uma das principais economias da América latina. A mais importante dessas medidas diz respeito a uma industrialização promovida pelo governo.

A condição necessária para os governos latinos conduzirem as economias rumo a novos horizontes reside na exigibilidade de agregar valor aos bens produzidos para serem exportados, com o objetivo de elevar os preços e criar maior competitividade.

A Cepal defende o estabelecimento de um mecanismo de proteção comercial pela periferia. Não como uma forma de imposição de fortes obstáculos às importações, mas sim como um protecionismo necessário ao período de transição da economia agrária para a industrial.

A solução proposta tem por objetivo gerar a diminuição das disparidades entre os centros e as periferias. Contudo, o cumprimento deste projeto demandaria poupanças domésticas a serem convertidas em investimentos e uma ampliação dos mercados internos. Considerando este entrave, há a sinalização, como via alternativa, da existência de sistemas preferenciais entre

\footnotetext{
7 Bens cuja demanda não varia positivamente com o aumento da renda são denominados economicamente de bens inferiores.

${ }^{8}$ MANTEGA, Guido, A Economia Politica Brasileira, Polis/Vozes, 1987, 4a .edição. p. 35
} 
países da América Latina. Da concepção dessas áreas emanam diversos benefícios para a região integrada, na medida em que cria condições para geração de poupanças domésticas e ampliação das escalas de produção devido à nova base produtiva calcada em um setor de alto valor agregado. O desenvolvimento seria viabilizado a partir da formação de nova demanda doméstica em cada país. A constituição deste mercado tornou-se, portanto, o ativo estratégico para o desenvolvimento de cada nação, o que se caracterizou no Modelo de Substituição de Importações (MSI). Todavia, o regionalismo hacia adentro da Cepal é, paulatinamente, substituído pelo regionalismo hacia afuera, bem mais poroso e adaptado à realidade globalizante que se acentua a partir dos anos 90 do século passado. É nesse quadro que emerge o Mercado Comum do Sul (Mercosul).

\section{Do MSI ao Mercosul: o lugar do Nordeste na federação brasileira}

A participação ativa do Estado brasileiro no processo de industrialização, consolidada nos moldes do MSI, gera um complexo produtivo amplo e diversificado, concentrado, sobretudo, no sudeste com alto potencial de acumulação e em bases monopolistas ou oligopolistas, que viabilizam as condições para uma integração econômica nacional. É, portanto, nesse contexto que se insere o atrelamento da região Nordeste à estrutura industrial do Sudeste, pois para a região adota-se uma estratégia de industrialização especializada em bens intermediários ${ }^{9}$, visando o mercado nacional e internacional, o que marcaria a industrialização nordestina a partir da década de $1970 .{ }^{10}$

Tal fato encontra explicações quando é possível apreciar não apenas regiōes marginais no contexto internacional, mas transmutá-las para as conjunturas nacionais. Desta forma, pode-se afirmar que houve no território brasileiro, com a estabilização da industrialização, a geração de pólos distintos: um deles calcado na transformação de bens com alto valor agregado - principalmente o estado de São Paulo e regiōes adjacentes, configurando estas as regiōes Sudeste e Sul - e outro, que permanece voltado para a produção de bens com baixo valor, as chamadas commodities - encontrando-se neste grupo, as regióes Nordeste, Norte e Centro-Oeste.

\section{Um quadro geral sobre a região nordeste é delineado por Celso Furtado ${ }^{11}$ :}

O Nordeste brasileiro, onde nasci e vivi até aos vinte anos, constitui o mais antigo núcleo de povoamento do Brasil. Após uma fase de prosperidade nos séculos XVI e

\footnotetext{
9 São denominados bens intermediários aqueles que não estão em seu estado natural, mas ainda necessitam agregar valor para se tornar um bem final.

10 Cf:: WANDERLEY, Livio A. O MERCOSUL e a Integração Mundial: Brasil, Nordeste e Bahia, União Européia MERCOSUL e Bahia: Novas relações Centro-Periferia, Salvador, 91 - 101. 1998.

$11 \mathrm{http}: / /$ www.academia.org.br/imortais/cads/11/celso2.htm (acessado em 7.4.2005)
} 
XVII, a regiáo conhece um longo declínio, o que explica que as estruturas sociais aí sejam mais rígidas que em qualquer outra área do país. A descoberta do ouro e dos diamantes nas Minas Gerais lhe retirou a preeminência econômica, e a transferência da capital da Bahia para o Rio de Janeiro significou a perda da preeminência política.

Socialmente, o Nordeste traz consigo os maiores problemas nacionais; com uma população maior que o somatório das populações dos parceiros do Mercosul, essa região serve de residência para $30 \%$ da população brasileira, abrigando cerca de $50 \%$ dos pobres do país, produzindo, contudo, apenas $17 \%{ }^{12}$ do PIB nacional ${ }^{13}$. Essa desigualdade no comportamento dos negócios do Nordeste se deve a histórica heterogeneidade de participação das regiōes no PIB brasileiro iniciada na troca de eixo econômico (monocultura da cana-deaçúcar nordestina para a mineração no centro-sul) e consolidada durante todo o período subseqüente da história da nação (a lavoura cafeeira e a insuficiente industrialização). Dessa dessemelhança emana, como conseqüência, o retrocesso de toda uma região, fazendo com que os estados nordestinos ocupem os nove últimos lugares no ranking do IDH brasileiro.

Nessa arena balizada por grandes desigualdades regionais brasileiras é assinado, em 26 de março de 1991, o Tratado de Assunção. Ele dá continuidade ao processo de Integração Regional na América Meridional, estabelecendo o Mercado Comum do Sul. ${ }^{14}$ No que tange o território nordestino, o Mercosul não é concebido no o intuito de reverter os desníveis apresentados; o projeto apresenta, em linhas gerais, como objetivos: a livre circulação de bens, serviços e fatores produtivos entre os países, por meio, entre outros, da eliminação dos direitos alfandegários e restrições não-tarifárias à circulação de mercadorias e de qualquer outra medida de efeito equivalente; o estabelecimento de uma

\footnotetext{
12 No ano de 2002, o PIB nordestino representava $13,52 \%$ do PIB nacional. Fonte: Instituto Brasileiro de Geografia e Estatística. http://www.ibge.gov.br/home/estatistica/economia/contasregionais/2002/ TPUFPIBpm.pdf (Acessado em 8.4.2005)

13 Cf. RECENA, João J. Guimarães. O Nordeste do Brasil face ao MERCOSUL e à Globalização. Centro de Estudos Konrad Adenauer Stiftung, São Paulo, no ${ }^{\circ}$, 163-168. 1998.

${ }^{14}$ Embora algumas tentativas preliminares tenham ocorrido já na década de 1950, os passos mais concretos no sentido da integração foram dados em 1960 com a criação da Alalc - Associação Latino-Americana de Livre Comércio, transformada em Aladi (Associação Latino-Americana de Integração) em 1980 e que já se colocava como objetivo de longo prazo a liberalização total do comércio entre todos os países-membro, ao mesmo tempo que favorecia a aproximação e busca de integração entre grupos menores, cujas condições econômicas e políticas fossem mais favoráveis. Foi no marco de tais aproximaçōes parciais que se firmaram, em 1986 - após a queda dos governos militares nos dois países, e sob forte impacto dos efeitos da crise da dívida externa - os acordos de cooperação entre o Brasil e a Argentina, com vistas a incrementar o comércio em setores chaves para as economias dos dois países, como petróleo, bens de capital, trigo e automóveis. Os avanços no processo de negociação e implementação desses acordos levaram à celebração, em 1988, do Tratado de Integração, contemplando a formação de um mercado comum, abrangendo as duas maiores economias da América do Sul. Pouco depois, em 1990, os vizinhos menores, Paraguai e Uruguai, que já tinham aqueles dois países como principais parceiros comerciais, formalizaram sua intenção de aderir ao bloco - o que levou, finalmente, à institucionalização do Mercosul, em março de 1991, com a celebração do já referido Tratado de Assunção. $C f$. KATZ, Frederico J., et al. Mercosul: Mudanças Necessárias. No. 5. Unicap.
} 
tarifa externa comum; a adoção de uma política comercial comum em relação a terceiros Estados ou agrupamentos de Estados; a coordenação de posições em foros econômico-comerciais regionais e internacionais; a coordenação de políticas macroeconômicas e setoriais entre os Estados-Parte; e o compromisso dos Estados-Parte de harmonizar suas legislaçôes, nas áreas pertinentes, para lograr o fortalecimento do processo de integração ${ }^{15}$. Desta forma, cabe a cada EstadoNação a harmonização das políticas internas para uma melhor distribuição dos benefícios da integração regional entre suas unidades subestatais.

Os fundamentos econômicos que dão suporte à constituição do Mercosul têm algumas semelhanças com o enfoque estruturalista do sistema CentroPeriferia de Prebisch, pois, apesar de ter um tratamento diferente, permanece na nova leitura desenvolvimentista da Cepal os atributos da inovação tecnológica e da inserção econômica internacional, os quais são objetivos estratégicos para transformação produtiva com equidade que sintetiza os princípios do então modelo neoestruturalista. ${ }^{16}$

Contudo, ao assumir compromissos externos, o Brasil finda por dificultar a prática de políticas internas de correção de desequilíbrios regionais. Sua massa crítica e postura de liderança política implicam em responsabilidades para com os seus parceiros. A participação do BNDES em financiamentos não nacionais, por exemplo, tem causado forte polêmica, e levado líderes nordestinos a se manifestarem contrários a ela. A distribuição harmônica dos benefícios trazidos pela integração regional se torna, pois, complexa.

Por um lado, o processo de globalização sob dominância financeira foi extremadamente desigual na distribuição de seus frutos, seja do ponto de vista econômico ou social. O estado nacional teve seu papel ainda mais diminuído em países que, como o Brasil, se inseriram no processo de globalização dos anos 90 de maneira subordinada e sem um projeto nacional. ${ }^{17}$

Existem ainda outros agravantes no que concerne aos atores políticos presentes nas negociações Nordeste - Brasil - Mercosul. O primeiro é a ideologia clássica das Vantagens Comparativas ${ }^{18}$, uma visão que se tornou hegemônica sobre o papel secundário do Nordeste brasileiro nas negociações com o Mercosul. Esse posicionamento afastado das potencialidades nordestinas serve, em diversas ocasiōes como explicação para a omissão Estatal no que se refere aos problemas regionais e seu consentimento na ampliação das desigualdades.

Um outro agravante - este de ordem social - para a marginalização nordestina é provocado pelo pensamento aristocrático ainda predominante na

\footnotetext{
15 Cf:: Art. 1. Tratado de Assunção.

16 Cf: : WANDERLEY, Livio A. Op. cit.

17 MATTOSO, Jorge. Relações internacionais e poder local: o caso de São Paulo. Política Externa, vol. 10, $n^{\circ}$ 3. Universidade de São Paulo. (GACINT-USP)

18 Cf. OLIVEIRA. Marcos A. Guedes de. Mercosul e Política. Editora LTR, 2001.
} 
própria região. A classe de maior influência econômica continua insistindo no velho modelo das vantagens comparativas, descomprometendo-se com a busca de alternativas e fazendo confirmar um modelo que consolida o atraso de todo o território. Com um quadro político marcado por fraturas, os discursos desse território sobre o Mercosul são marginais e pouco articulados. Assim, a posição nordestina frente ao Mercosul é bastante delicada. Isso advém da própria dinâmica competitiva da integração que, de uma forma geral, é vantajosa para as economias mais bem preparadas. $\mathrm{O}$ que, significativamente, não enquadra o Nordeste brasileiro.

A experiência dessa região com o Mercosul torna visível um relativo isolamento em relação aos benefícios da Integração Regional. Se as exportações nordestinas para o Mercado Comum do Sul aumentam de 3,21\% em 1990 para 9,56\% em 1994, sua participação no total brasileiro exportado no mesmo período diminui de 7,53 para $5,53^{19}$. Apesar de crescentes, as negociações Nordeste - Mercosul ainda continuam muito concentradas tanto territorial como setorialmente nos núcleos de maior competitividade da região ${ }^{20}$. A estratégia de integração mercosulina parece não considerar devidamente a heterogeneidade intrínseca de cada parte a ser integrada. Vê-se o Estado-nação como um todo, e não por meio de suas contradições ou frações componentes. A ela falta vocação distributiva e emancipadora.

\section{Enquadramento jurídico e prerrogativas estatais}

O balizamento normativo estabelecido pela Carta Magna, pelas Constituiçōes estaduais e Leis Orgânicas Municipais tem grande relevância para a melhor compreensão dos impactos do Mercosul na economia política dos estados de Pernambuco, Bahia, São Paulo e Rio Grande do Sul (e de suas municipalidades capitais), pois é também pelos fundamentos emanados dessas legislaçōes que se pode auferir a intensidade do movimento de integração regional.

Promulgada três anos antes do estabelecimento do Tratado de Assunção, a Constituição brasileira traz no corpo de seu texto princípios que possibilitam articular a conformação de uma aliança latino-americana. ${ }^{21}$ Neles identifica-se

19 Cf. PORTELA, Aloísio. Mercosul vai prjudicar o NE. Diário de Pernambuco, 8.10.1995.

20 Cf. VERSIANI, Isabel. Mercosul beneficia regiōes Norte, Nordeste e Centro-Oeste. Gazeta Mercantil, 8.5.1997.

21 Art. $4^{\circ}$. ipsis verbis:

A República Federativa do Brasil rege-se nas suas relações internacionais pelos seguintes princípios:

I - independência nacional; II - prevalência dos direitos humanos; III - autodeterminação dos povos; IV - não intervenção; V - igualdade entre os Estados; VI - defesa da paz; VII - solução pacífica dos conflitos; VIII - repúdio ao terrorismo e ao racismo; IX - cooperação entre os povos para o progresso da humanidade; X - concessão de asilo político.

Parágrafo único: A República Federativa do Brasil buscará a integração econômica, política, social e cultural dos povos da América Latina, visando à formação de uma comunidade latino-americana de nações. 
a importância dada pelo Estado-nacional brasileiro à integração econômica, política, social e cultural dos povos latinos da América, visando à formação de uma comunidade de nações. Uma análise da tripartição dos poderes dentro das esferas federal, estadual e municipal - inserida num contexto de abertura econômica e comercial e alianças políticas - se faz mister para uma compreensão da forma por meio da qual os estados de Pernambuco, Bahia, São Paulo e Rio Grande do Sul e as municipalidades de Recife, Salvador, São Paulo e Porto Alegre podem ser influenciados e situados na integração do Cone Sul da América Meridional.

Situado num quase consenso de democracia de mercado, o pacto federativo brasileiro tenta refletir, por um lado, uma descentralização focada em mais participação cidadã e, por outro lado, uma preocupação de gestão competente, de visão global e calcada em parâmetros de eficiência. Estados e municípios emergem, pois, como os vetores-mor dessa participação, cabendo à União competências de planejamento e articulação internos e externos.

Desse modo, algumas consideraçôes sobre a problemática dos estados e municipalidades podem ser tecidas antes do delineamento normativo estabelecido pelas leis vigentes em cada esfera, pois existe uma tendência visando dar-lhes maiores poderes de decisão dentro de um novo cenário internacional. Como assinala Jorge Mattoso ${ }^{22}$ :

(...) as cidades e os governos locais comprometidos com o desenvolvimento e a distribuição de renda devem transformar-se em protagonistas de uma nova política de inserção social e cidadã. Seu desafio maior é a expansão de políticas urbanas de infra-estrutura e de inclusão social visando ao desenvolvimento sustentável, vital para a sobrevivência humana e da democracia nesses grandes aglomerados urbanos.

(...) Por isso, torna-se também imprescindível às autoridades locais uma visão ampla, capaz de favorecer a pressão sobre os governos nacionais, por políticas menos subordinadas aos mercados financeiros; sobre os projetos de integração regional como o Mercosul, por seu aprofundamento e superação das atuais dificuldades; sobre os organismos internacionais, por relaçôes diretas com aglomeraçôes urbanas; e pela criação de uma outra institucionalidade internacional, mais solidária, socialmente regulada e justa.

Nesse sentido, pode-se assinalar as articulações entre estados brasileiros e províncias argentinas no quadro da dinâmica Crecenea/Codesul, como também a recente decisão do Conselho Mercado Comum n ${ }^{\circ} 41 / 04$ criando o Foro Consultivo de Municípios, Estados Federados, Províncias e Departamentos do Mercosul. Sem falar de uma quase para-diplomacia por parte de algumas unidades subnacionais da União Européia e da atuação do seu Comitê de Regiōes na arena institucional comunitária.

22 Secretário municipal de Relações Internacionais durante a gestão de Marta Suplicy. Cf. MATTOSO, Jorge. Relações internacionais e poder local: o caso de São Paulo. Política Externa, vol. 10, no 3. 


\section{O Legislativo}

O Poder Legislativo, representado na esfera federal pelo Congresso Nacional, o qual é composto pela Câmara dos Deputados e pelo Senado Federal, possui atribuições limitadas no que diz respeito aos atos, acordos ou tratados internacionais. Todavia, é de sua competência exclusiva regulá-los quando estes acarretam encargos ou compromissos gravosos ao patrimônio federal ${ }^{23}$. Cabe ainda estritamente ao Poder Legislativo nacional, pelos poderes emanados da União, a legislação sobre o comércio exterior no âmbito nacional, estadual e municipal, tendo em vista que o intercâmbio de bens e serviços é controlado por lei federal.

No que concerne o Poder Legislativo estadual, este é representado pelas Assembléias Legislativas que, no âmbito do estudo desenvolvido e dentro do balizamento das respectivas constituições das unidades federativas, não desenvolvem imputações ligadas à legislação sobre a abertura político-econômica mencionada, cabendo ao estado, pelo artigo 25 da Constituição Federal, estabelecer leis observando os princípios da Carta Magna. ${ }^{24}$

Ausências semelhantes podem ainda ser confirmadas no que diz respeito às Câmaras Municipais. Essas, assim como as respectivas Assembléias Legislativas dos estados mencionados não dispõem de meios para deliberar sobre relações internacionais, mesmo que essas impliquem em maiores vantagens comparativas para o município. O legislativo municipal deve proceder em consonância com a regência da Lei Orgânica que, por sua vez, encontra-se limitada pelas disposições presentes na Constituição Federal, como dirige o artigo 26 da mesma, e pelas Constituições dos respectivos estados. ${ }^{25}$

\section{O Executivo}

No que tange às prerrogativas do Poder Executivo nacional, dentro do contexto de alianças interestatais, estas versam, de maneira simplificada, sobre a manutenção das relações com Estados estrangeiros e a celebração de tratados e atos internacionais, executados pelo presidente da República, cabendo ao Congresso Nacional o referendo no que concerne possíveis atitudes tomadas pelo presidente, como prevê os artigos 21 e 49 da Magna Carta. Uma outra atribuição do Poder Executivo dentro deste plano, é a alteração, atendidas as condiçóes e limites estabelecidos em lei, das alíquotas dos impostos de importação de produtos estrangeiros e exportação de produtos nacionais ou nacionalizados ${ }^{26}$.

\footnotetext{
23 Cf. artigo 49. C.F., 1988.

${ }^{24}$ Cf. artigo 25. C.F., 1988.

25 Cf. artigo 26. C.F., 1988.

26 Cf: : artigo 153. C.F., 1988.
} 
O comportamento do Poder Executivo nas esferas estaduais tem características peculiares quando da observação dos entes federados Pernambuco, Bahia, São Paulo e Rio Grande do Sul. Na Constituição da Bahia existe, no artigo 105, inciso XVII, uma atribuição que aponta para uma incipiente competência municipal no cenário internacional, pois concede ao governador do estado poderes para "contrair empréstimos externos ou internos e fazer operaçôes ou acordos externos de qualquer natureza, após autorização da Assembléia Legislativa, observada a Constituição Federal"27. As restantes, por seu turno, nada apresentam no que tange a ampliação do poderes do governador na esfera internacional, sendo as decisóes internacionais tomadas apenas na esfera da União.Todavia, o silêncio das constituições estaduais não significa que os Executivos dos entes federados não possam adotar políticas institucionais que contemplem a esfera internacional. Isso, claro, dentro dos limites estabelecidos pela Carta Magna. Tais são os casos de Rio Grande do Sul e São Paulo ou Minas Gerais que instituíram órgãos de assuntos internacionais para tratar dos seus respectivos interesses nessa esfera de $\operatorname{poder}^{28}$. Essas secretarias agem, em consonância com o Ministério das Relaçôes Exteriores (MRE) e/ou o Ministério do Desenvolvimento, Indústria e Comércio Exterior (MDICE), tanto no nível externo propriamente dito, e.g. através de ações de promoção comercial; quanto no nível interno, por meio da defesa dos interesses estaduais junto a esses mesmos ministérios ou ainda a outras instâncias federais do Executivo, Legislativo e Judiciário. Gerando o que Kincaid denomina de constituent diplomacy ${ }^{29}$.

Os atores políticos das municipalidades dentro do Poder Executivo, comportam-se de maneira similar aos considerados no poder legislativo. Com pouca autonomia para discorrer sobre assuntos de âmbito internacional, os prefeitos devem agir segundo as diretivas emanadas dos respectivos governadores e do presidente da República. Mas, como no caso dos estados, isso não impede algumas cidades de articularem a criação de secretarias de relações internacionais, como o fizeram as cidades de Belo Horizonte, Porto Alegre, Salvador, São Paulo, Santa Maria, as quais se esforçam em promover, ainda uma vez como as dos estados, uma participação mais ativa da urbe no processo de globalização ${ }^{30}$.

\footnotetext{
27 Cf. artigo 105, Constituição da Bahia, 1989.

${ }^{28}$ O Rio Grande do Sul possui uma Secretaria do Desenvolvimento e dos Assuntos Internacionais (http:/ /www.sedai.rs.gov.br/) ; São Paulo um Conselho Estadual de Relaçōes Internacionais e Comércio Exterior (http://www.democraciaparticipativa.org/Arquivos/inst_conselhos_sp.htm); Minas Gerais uma SubSecretaria de Assuntos Internacionais (http://www.ppp.mg.gov.br/downloads.htm).

${ }^{29}$ KINCAID, John. Constituent Diplomacy in Federal Polities and the Nation-state: Conflict and Cooperation. In: MICHELMANN, Hans J., SOLDATOS, Panayotis, Federalism and International Relations: The Role of Subnational Units, OUP,Oxford, 2001.

${ }^{30}$ Nos dias 2 e 3 de junho foi realizado, em parceria com a Secretaria Extraordinária de Relaçōes Internacionais do Município de Salvador, o I Fórum Nacional de Secretarias de Relações Internacionais das Cidades no Salão Atlântico do Tropical Hotel da Bahia.
} 


\section{O Judiciário}

Por fim, no que diz respeito à relação entre o Poder Judiciário e as relações internacionais, este tem atribuições apenas no âmbito federal, sendo inativo quanto às questões analisadas no âmago estadual e inexistente na esfera municipal. De forma simplificada, é de competência do Judiciário nacional, por meio do Supremo Tribunal Federal ${ }^{31}$, Superior Tribunal de Justiça ${ }^{32}$ e dos juízes federais ${ }^{33} \mathrm{o}$ julgamento das causas entre Estado estrangeiro ou organismo internacional e os entes federados ou pessoa domiciliada ou residente no país.

Ao término do exame da Constituição Federal, das Constituições Estaduais e das Leis Orgânicas Municipais dentro do contexto da abertura comercial e da integração regional, é possível afirmar que inexistem, nesse nível, quaisquer legislaçōes voltadas, stricto sensu, para a Integração do Cone Sul. A exceção reside, como já assinalado, no artigo quarto da C.F. que vislumbra os princípios norteadores das relaçóes internacionais da República Federativa do Brasil, ancorados numa perspectiva monolítica e estatocêntrica.

\section{Atores políticos e agentes econômicos subnacionais}

A abertura comercial e, posteriormente, o Mercosul, alteram, consideravelmente, o contexto no qual estavam inseridos tanto agentes econômicos como atores políticos brasileiros. Faz-se, assim, mister uma nova forma de adequação comportamental visando, agora, não apenas ao cenário nacional como também toda à movimentação internacional. Essa adequação de comportamentos tem por objetivos de um lado, a maximização dos lucros e a inserção empresarial em novos mercados e, por outro, a inclusão da União, estados e municípios dentro do universo globalizado.

No que diz respeito aos estados setentrionais de Pernambuco e Bahia e as municipalidades de Recife e Salvador algumas alteraçóes vêm existindo quando da abertura econômica/comercial e do Mercosul. No caso do estado da Bahia, apesar de uma constituição inovadora, a praxis dos poderes subnacionais parece não refletir, de facto, as potencialidades de jure.

Tal fato encontra simetria em Pernambuco, pois, embora esse estado federado não possua uma Constituição que outorgue poderes de cunho internacional ao executivo, como a baiana, na Assembléia Legislativa do estado pernambucano existe uma comissão voltada para assuntos internacionais cujo presidente é o deputado estadual Manuel Ferreira (PFL) - que têm por objetivo, entre outros, fomentar atividades comerciais e culturais vinculadas

\footnotetext{
31 Cf. artigo 102, C.F., 1988.

32 Cf. artigo 105, C.F., 1988.

33 Cf. artigo 109, C.F., 1988.
} 
ao Mercosul. Ainda que não existam projetos ligados à possibilidade de emendar a Constituição, pois, segundo o assessor do deputado, Vicente Filho ${ }^{34}$, "não há ainda temas para serem levados à votação, devido à estruturação da comissão", que, agora, volta-se para o estudo do panorama pernambucano dentro do contexto internacional. A preocupação do poder legislativo do estado de Pernambuco é singular não apenas no contexto nordestino, mas, juntamente com os estados de São Paulo e Rio Grande do Sul compõem um grupo de estados dispostos a estudar as influências de um novo cenário internacional dentro das respectivas unidades federativas.

Possivelmente, dentro do contexto observado, o ator político de maior preponderância venha a ser a Secretaria de Desenvolvimento Econômico do município do Recife que, por meio de um "Diálogo Econômico Local" visa ao estreitamento das relaçóes recifenses com as cidades integrantes da rede de cidades interligadas denominadas Mercocidades ${ }^{35}$.

Essa secretaria do Poder Executivo municipal, cuja atuação evoluiu consideravelmente nos últimos quatro anos, durante a gestão do prefeito João Paulo Lima e Silva (PT), tem por objetivos não apenas estreitar relações entre os municípios participantes da rede, na qual estão inseridos os municípios nordestinos de Recife, Mossoró, Fortaleza e Salvador ${ }^{36}$, mas também, segundo o diretor de competitividade e captação de investimentos, Rodolfo Guimarães "levar uma imagem do Brasil para o exterior diferente do Rio de Janeiro, Foz do Iguaçu e da Amazônia, atraindo assim o turismo, além de outros benefícios emanados da abertura" 37 .

O comportamento do órgão acima observado trás uma nova tendência na qual, segundo Rodolfo Guimarães, "o município vem tornando-se protagonista das decisōes políticas" descentralizando decisões antes atribuídas ao Poder Executivo Estadual, obtendo, desta forma, maior autonomia no contexto internacional; ainda assim, apesar da inovação política, a Secretaria Municipal, embora vise a estratégias de articulação horizontal, não desenvolve projetos voltados de maneira especifica para o Mercosul. Pode-se, igualmente, assinalar a criação de uma Secretaria de Relações Internacionais em Salvador em janeiro de 2005. A mesma vem, aos poucos, articulando-se para promover a inserção global do município.

\footnotetext{
34 Entrevista concedida no dia 27.4.2004 na Assembléia Legislativa de Pernambuco.

35 As origens das Mercocidades começaram em março de 1995, data na qual celebrou-se na cidade de Assunção o seminário "Mercosul: Oportunidades e Desafios para as Cidades" organizada pela Uniāo de Cidades Capitais Ibero-Americanas - sub-regional Cone Sul. Nessa ocasião, as cidades capitais do Cone Sul assinaram a Declaração de Assunção na qual expressavam a vontade de criar una rede de Cidades do Mercosul denominada Mercocidades.

36 No site www.pbh.gov.br/mercocidades, o município de Mossoró encontra-se inserido no grupo das mercocidades como membro postulante.

37 Entrevista concedida no dia 29.4.2004.
} 
No âmago dos agentes econômicos estaduais, dois merecem destaque por sua inserção dentro do universo estadual. A Fiepe (Federação das Indústrias do Estado de Pernambuco) e a Fieb (Federação das Indústrias do Estado da Bahia) têm grande importância dentro da análise a ser desenvolvida, pois são os representantes de um importante setor da economia.

A Fiepe, atuando por meio do CIN (Centro Internacional de Negócios) e do Conselho Temático de Comércio Exterior, visa à busca de uma maior inserção mercadológica internacional, disponibilizando inúmeros programas, desde fontes de dados a acordos de cooperação, em apoio ao setor empresarial, com especial ênfase às pequenas e médias empresas. Dotada de diversos acordos e programas, a instituição promove não apenas a exportação de bens e serviços mas, da mesma forma, faz alianças buscando captação de investimentos, cooperação cientifica e tecnológica entre outras atribuições. Vale registrar que, apesar do incentivo dado para a melhoria da competitividade pernambucana, a Fiepe não desenvolve um intercâmbio concreto com o Mercosul ${ }^{38}$, mas desenvolve para essa integração seminários de capacitação, estudos e no ano de 2003 uma missão para a Argentina, além da emissão de certificados de origem ${ }^{39}$. Por fim, a Fieb, também através do seu CIN (Centro Internacional de Negócios), desenvolve cursos, seminários e palestras sobre temas específicos de comércio exterior, contribuindo desta forma, para o aprimoramento da capacitação do empresariado baiano perante a globalização.

A atuação dos agentes econômicos e atores políticos pernambucanos e baianos dentro de um novo cenário internacional pode ser considerada pouco significativa, pois não se pode constatar avanços concretos que justifiquem a mudança normativa, no âmbito das legislações, e/ou políticas regionais voltadas para uma maior competitividade dos estados. No que diz respeito ao Mercosul, embora consolidada a zona de livre comércio há mais de 13 anos e a União Aduaneira há quase 10 anos $^{40}$, sua influência na mobilização das Unidades Federativas analisadas é de pequena envergadura, dificultando assim um maior volume de comunicação entre as unidades subnacionais e seus países membros.

Considerando a diferenciação de atores políticos e agentes econômicos e analisando por seu turno os estados meridionais de São Paulo e Rio Grande do Sul e suas respectivas municipalidades de São Paulo e Porto Alegre, pode-se observar uma maior comunicação entre esses e os membros mercosulinos, visando a uma maior conexão, de forma a aumentar os possíveis e efetivos benefícios emanados da integração.

\footnotetext{
${ }^{38}$ A Fiepe mantém parcerias com o Chile, EUA e a Europa, sendo com essa última por meio do eurocentro. 39 Certificados de Origem são notas emitidas por determinados órgãos visando a registrar determinado bem como originado do Mercado Comum, recebendo uma carga tributária menor do que se fosse emanado de outro país ou região.

40 Embora a União Aduaneira exista há quase 10 anos, conserva-se ainda uma lista de exceções para determinados produtos fabricados pelos países integrantes (e.g. açúcar, automóveis).
} 
A atuação dos atores políticos estaduais meridionais encontra certa semelhança quando comparada ao estado pernambucano. Pois, como esse, o estado de São Paulo e o estado de Rio Grande do Sul possuem, ao nível de seus legislativos, uma comissão - permanente ou não - voltada para a análise dos efeitos da abertura comercial, e mais especificamente os efeitos do Mercosul dentro dos domínios estaduais.

As citadas comissões - diferentemente do que ocorre no estado pernambucano - buscam a coordenação parlamentar entre os legislativos estaduais de São Paulo e Rio Grande do Sul com os países integrantes do Mercosul. Além disso, no caso gaúcho, a Comissão Permanente do Mercosul apresenta ainda uma ampliação de interesses ao enumerar outros objetivos, tais como: acompanhar a implantação e evolução de acordos do Mercosul, em especial os referentes a normas técnicas e aos assuntos de política agrícola, fiscal, aduaneira, comercial, industrial, meio ambiente, segurança pública, sanitária, saúde, cultural, cidadania e políticas macroeconômicas, visando, a Comissão Permanente do Mercosul, a uma inserção aprofundada do estado gaúcho dentro do arcabouço iniciado em 1991.

Dentro do contexto municipal, ainda é possível estabelecer analogia com o estado de Pernambuco, pois as prefeituras municipais de São Paulo e Porto Alegre possuem também secretarias que têm em vista a inserção do poder local dentro das novas tendências internacionais. No âmago paulistano, a existência da Secretaria Municipal de Relações Internacionais - SMRI, que, fundada durante o governo da prefeita Marta Suplicy (PT) visa reinserir São Paulo no cenário internacional, trouxe consideráveis inovações para o contexto municipal na medida em que para consolidar tal objetivo, vem concentrando sua atuação em alguns eixos, sendo o principal a participação ativa nas redes internacionais de cidades. Neste ponto, a despeito do Mercosul, uma consideração de Jorge Mattoso $^{41}$, secretário municipal de Relaçôes Internacionais da Prefeitura de São Paulo na gestão Suplicy, é relevante no que tange à importância desta rede de cidades, para o município de São Paulo:

A rede mercocidades, por exemplo, que congrega mais de sessenta cidades de países membros do Mercosul, tem tido um papel relevante no intercâmbio de experiências de gestão pública por meio de suas atividades temáticas e na maior participação das cidades na estrutura e nas políticas do Mercosul, viabilizada a partir da criação da REMI Reunião Especializada de Municipalidades e Intendentes - a qual compõe o Grupo Mercado Comum (GMC) do Mercosul.

No que concerne à municipalidade de Porto Alegre, a Secar (Secretaria Extraordinária de Captação de Recursos e Cooperação Internacional) possui

${ }^{41}$ MATTOSO, Jorge. Relações internacionais e poder local: o caso de São Paulo. Política Externa, vol. 10, $\mathrm{n}^{\circ}$ 3. Universidade de São Paulo. (Gacint-USP) p. 117 
atributos que visam ao desenvolvimento local. Subdividida em dois setores, captação de recursos e cooperação internacional, esta secretaria busca, por meio do primeiro, coordenar e elaborar estudos e projetos necessários para a obtenção de financiamentos e promover a captação de recursos externos às finanças municipais, tendo como objetivo a viabilização de projetos definidos pela administração municipal, a partir da identificação de fontes de financiamento nacionais e internacionais. No que diz respeito às atribuições do setor de cooperação internacional, estas visam estabelecer e coordenar a política de intercâmbio e cooperação multilateral e bilateral com cidades, instituições e organizações não-governamentais. Elabora e executa políticas de projeção internacional da cidade, além de desenvolver atividades relacionadas com a função de integrante da Rede de Cidades do Mercosul (Mercocidades).

Pode-se citar, ainda, como atores políticos de relevo dentro das esferas estaduais, as secretarias de Comércio Exterior (Secex), representada, no âmbito estadual por gerências inseridas nas secretarias da Fazenda dos entes federados; e o Banco Nacional de Desenvolvimento Econômico e Social. No que diz respeito às primeiras, estas executam políticas, por meio de benefícios fiscais voltados para uma melhora no saldo comercial no âmbito nacional ${ }^{42}$, não existindo, desta forma, incentivos por parte do Poder Executivo estadual no incremento comercial com o Mercosul. O BNDES não executa, a seu turno, políticas regionais ou setoriais voltadas para a integração regional, contudo, desenvolve uma política de financiamento direcionada a favorecer fabricantes de autopeças da Argentina, que posteriormente será ampliada aos demais setores e aos outros membros. $\mathrm{O}$ intuito desse ato é de intensificar a ligação entre os Estados-Parte do Mercado Comum do Sul. Ainda nesse mesmo intuito foi criado pela Decisão n ${ }^{\circ}$ 45/04 o Fundo de Convergência Estrutural do Mercosul, que visa precisamente financiar programas para promover a convergência estrutural, desenvolver a competitividade, promover a coesão social - em particular das economias e regiōes menores e menos desenvolvidas - e apoiar o funcionamento da estrutura institucional e o fortalecimento do processo de integração. $\mathrm{O}$ que, pari passu, representa um vetor redistributivo que privilegia a alocação de recursos segundo uma lógica subnacional; e conseqüentemente um instrumento de atenuação da dicotomia centro-periferia.

Por fim, dos agentes econômicos imersos nas conjunturas estaduais dos entes meridionais, o que merece maior destaque vem a ser a Fiesp - Federação das Indústrias do Estado de São Paulo que, por meio da Área de Relações Internacionais e Comércio Exterior e do Conselho de Comércio Exterior acompanha todos os acontecimentos relacionados aos acordos bilaterais e negociações internacionais que afetam a indústria nacional. Ela também

42 Políticas são instituídas pelo Ministério do Desenvolvimento da Indústria e do Comércio adquirindo caráter uniforme dentro da União. 
disponibiliza orientações técnicas e assessoria para negócios voltados para o exterior. Por meio do conselho, a Fiesp acompanha os assuntos relativos à legislação e políticas voltadas para essa área, identifica problemas e propõe medidas de promoção dos negócios internacionais. Apesar de não expor políticas voltadas para o Mercosul, a Fiesp delimita a importância desta integração quando a circunscreve como "o mais importante meio de inserção do país no contexto internacional e sua grande resposta aos desafios impostos pela globalização". ${ }^{3}$

O desempenho dos atores políticos e agentes econômicos meridionais, comparativamente aos setentrionais, estão em uma posição de vanguarda, pois tendem a dinamizar os fluxos políticos comerciais entre os dois estados: São Paulo e Rio Grande do Sul com os membros do Mercado Comum do Sul, de tal forma que possibilitam ampliar a influência dele nesses estados. Embora não existam alterações no domínio normativo, a crescente importância da integração para os estados federados paulista e gaúcho pode ser notada pela da recorrência feita por esses, por meio de seus representantes acima enumerados, quando delimitam a relevância da abertura econômica via integração comercial em seus territórios.

\section{O comércio subnacional e o Mercosul}

A evolução quantitativa do volume comercializado torna-se relevante na medida em que se ambiciona verificar os resultados decorrentes dos trâmites entre os estados brasileiros analisados, a saber: Pernambuco, Bahia, São Paulo e Rio Grande do Sul, e o Mercado Comum do Sul. Busca-se, dessa forma, contemplar a participação do Mercosul na pauta de exportações das unidades federativas em apreciação e sua importância nos fluxos que proporcionam melhoras nos termos de intercâmbio. Assim, aspira-se a observar a possibilidade de mudanças no quadro dos principais destinos das exportações dos referidos estados e a possibilidade de melhoras nos termos de troca provenientes da união entre Brasil, Argentina, Paraguai e Uruguai, por meio do Tratado de Assunção, em 1991.

Embora o Mercosul não tenha sido delineado nos moldes hacia adentro da Comissão Econômica para a América Latina, ainda assim a introdução desse mercado comum hacia afuera traz muitos resultados semelhantes aos esperados por essa comissão. Apesar de não estar inserido diretamente no conjunto solução, o Mercado Comum do Sul oferece vias alternativas que visam a resolver os problemas elucidados pelo economista argentino e sua equipe de pensadores. Contudo, não se pode afirmar que ele tenha proporcionado per se todos os desdobramentos enumerados, mas a presença do Mercosul na realidade dos entes federados favorece a hipótese de que os sistemas preferenciais podem promover uma agregação de valor dos bens transacionados e desse modo minorar as discrepâncias entre centros e periferias.

43 www.fiesp.org.br 
No que tange os estados nordestinos, a presença do Mercosul como destinatário para bens produzidos pela mais pobre região brasileira pode ser considerada em expansão tendo em vista que as exportaçóes pernambucanas para com esse destino cresceram $29,69 \%$ e as baianas $103,7 \%$ entre os anos de 2000 e $2005^{44}$. Quando comparados com a média nacional $(15,24 \%)$ e com a média dos demais estados analisados (Rio Grande do Sul - 20,60\% e São Paulo - 4,54\%), é possível inferir que o Mercosul, em termos relativos, vem ampliando sua participação dentro do contexto nordestino. Embora, quando relacionado com a média nacional absoluta, a presença desses estados nas exportações totais para a integração seja consideravelmente menor que os demais estados ${ }^{45}$, ainda assim é possível observar que os mesmos vêm ampliando consideravelmente suas presenças dentro do contexto absoluto provocado pela integração mercosulina.

Ainda que o crescimento das exportações destes entes federados meridionais frente ao Mercado Comum do Sul possa ser significativo, no que concerne melhoras nos termos de intercâmbio, os impactos causados pelo Mercosul são diferenciáveis e, até certo ponto, ambíguos. Tendo em vista que efeitos semelhantes podem ser encontrados entre centros e periferias. Um fato a ser considerado diz respeito aos efeitos da integração sobre a Bahia e o Rio Grande do Sul. Pelos gráficos 1 e 2, é possível observar que os bens exportados por esses são ainda pobre em valor agregado e que o Mercosul nem sempre possibilita melhoras nos termos de intercâmbio para esses estados. A análise desse fator pode ser observada pelo fato de que as quantidades exportadas são quase sempre maiores que os respectivos valores em dólares. Isso fica tangível quando se contrapóe o volume exportado em unidades de massa e em unidades monetária. Como as primeiras quase sempre excedem as segundas, é possível inferir que os bens não possuem alto valor agregado e que o Mercosul não traz, sempre, melhoras aos termos de intercâmbio para os respectivos estados.

\footnotetext{
44 Os dados analisados são originados do sistema aliceweb, do Ministério do Desenvolvimento da Indústria e do Comércio (acessado em 11.4.2005).

45 Pernambuco, no ano de 2000, representava apenas 0,50\% das exportações totais para o Mercosul e a Bahia 3,8\%. Em 2004, as exportaçôes pernambucanas atingiram 2,71\% e as baianas passaram a representar 6,73\%. O estado do Rio Grande do Sul saiu de 12,89\% em 2000 para 13,49\% em 2004 e o estado de São Paulo decresceu, saindo de 51,02\% em 2000 para 42,34\% em 2004.
} 


\section{Gráfico 1}

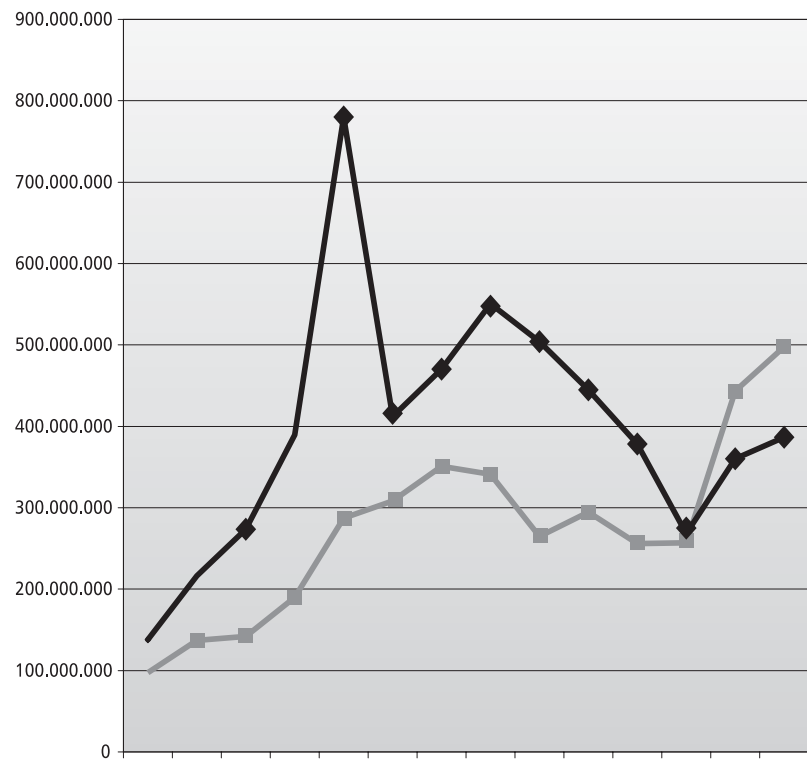

- Volume Exportado pela Bshis para o Mercosul em kg

Exportações baianas para o Mercosul em US\$

19911992199319941995199619971998199920002001200220032004

\section{Gráfico 2}

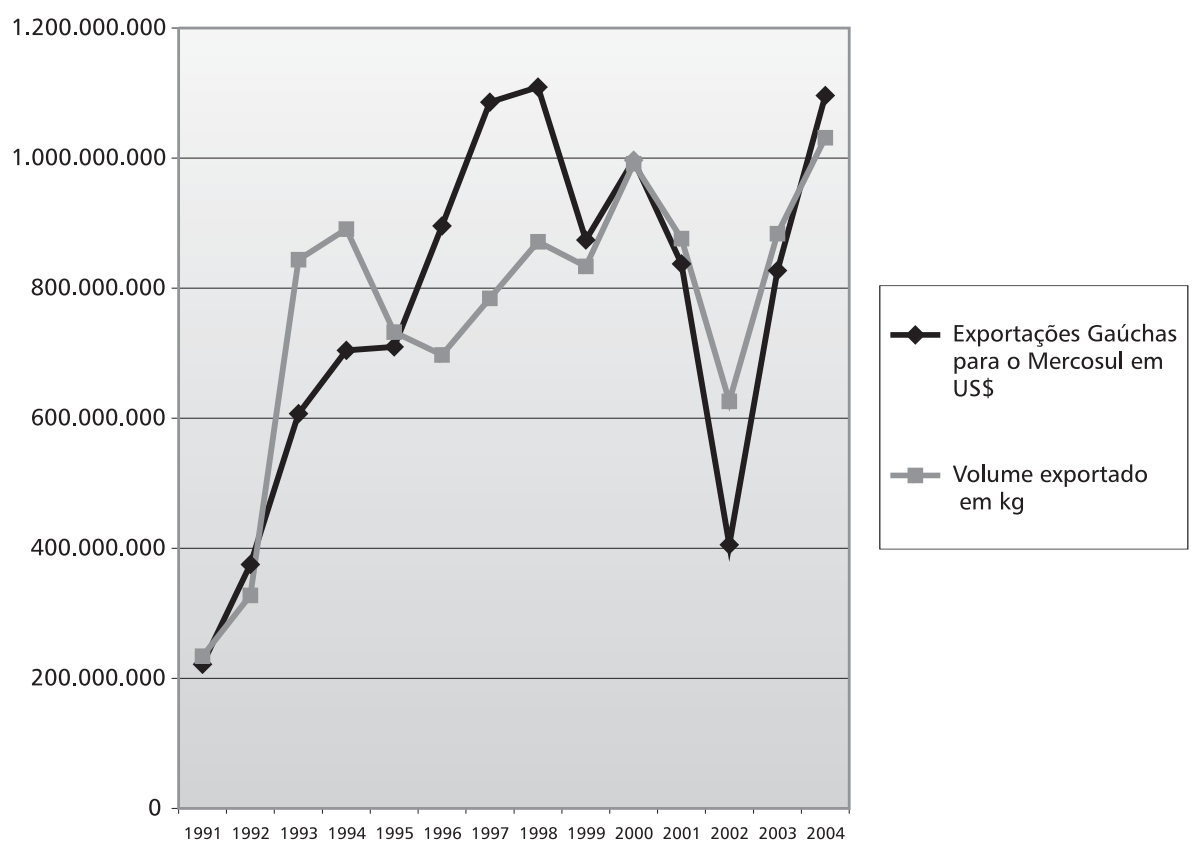


Apesar disso, merece consideração o fato que as exportações gaúchas para o Mercosul, obtêm melhoras nos termos de troca durante o período em que o Brasil empreende o regime de câmbio fixo. Durante esse período, Rio Grande do Sul passa a exportar uma menor quantidade com maiores preços. No caso da Bahia essa tendência aparece a partir de meados de 2002.

Por outro lado, percebe-se uma semelhança entre os efeitos causados pelo Mercado Comum do Sul nos estados de São Paulo (gráfico 3) e Pernambuco (gráfico 4). Em ambos os casos, os termos de troca os favorecem, tendo em vista a presença de bens com maior valor agregado presentes nos bens com destino ao Mercosul, exceto para um pequeno período para o estado de Pernambuco.

\section{Gráfico 3}

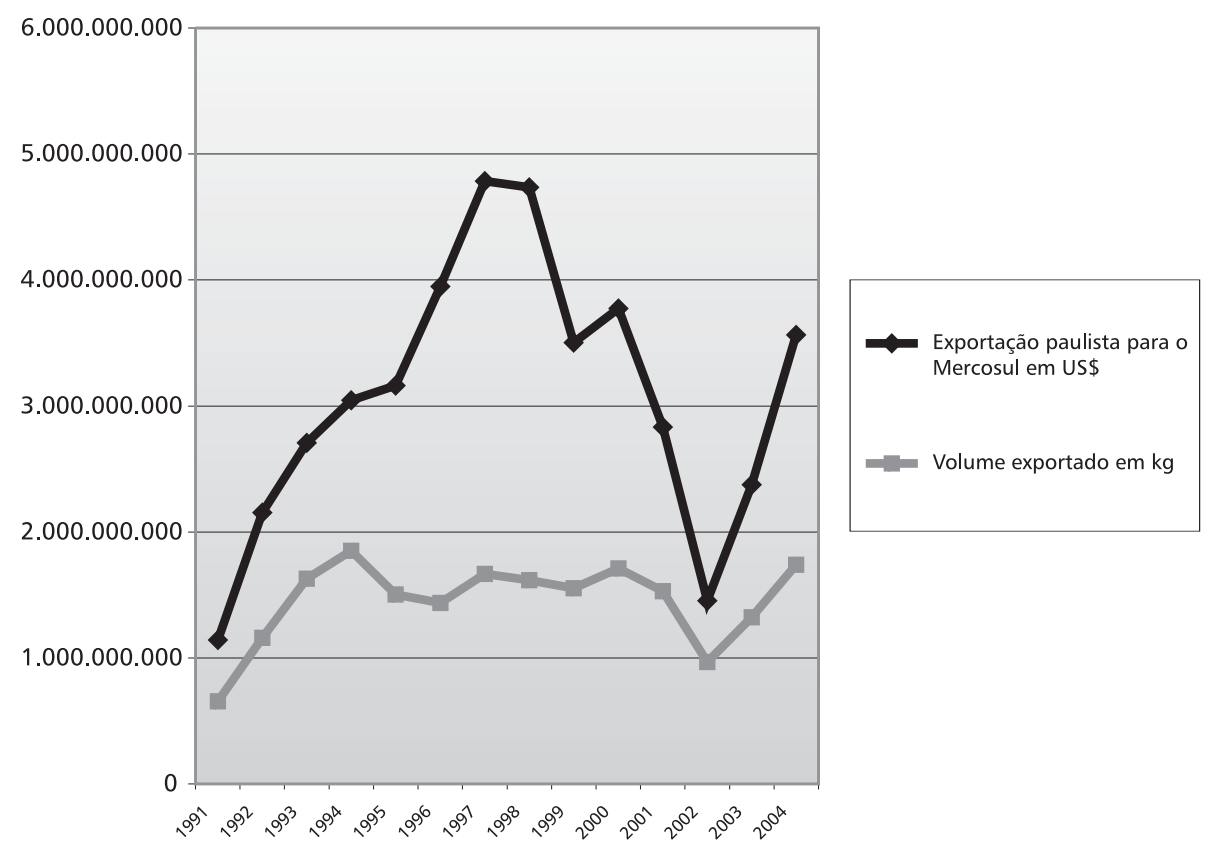




\section{Gráfico 4}

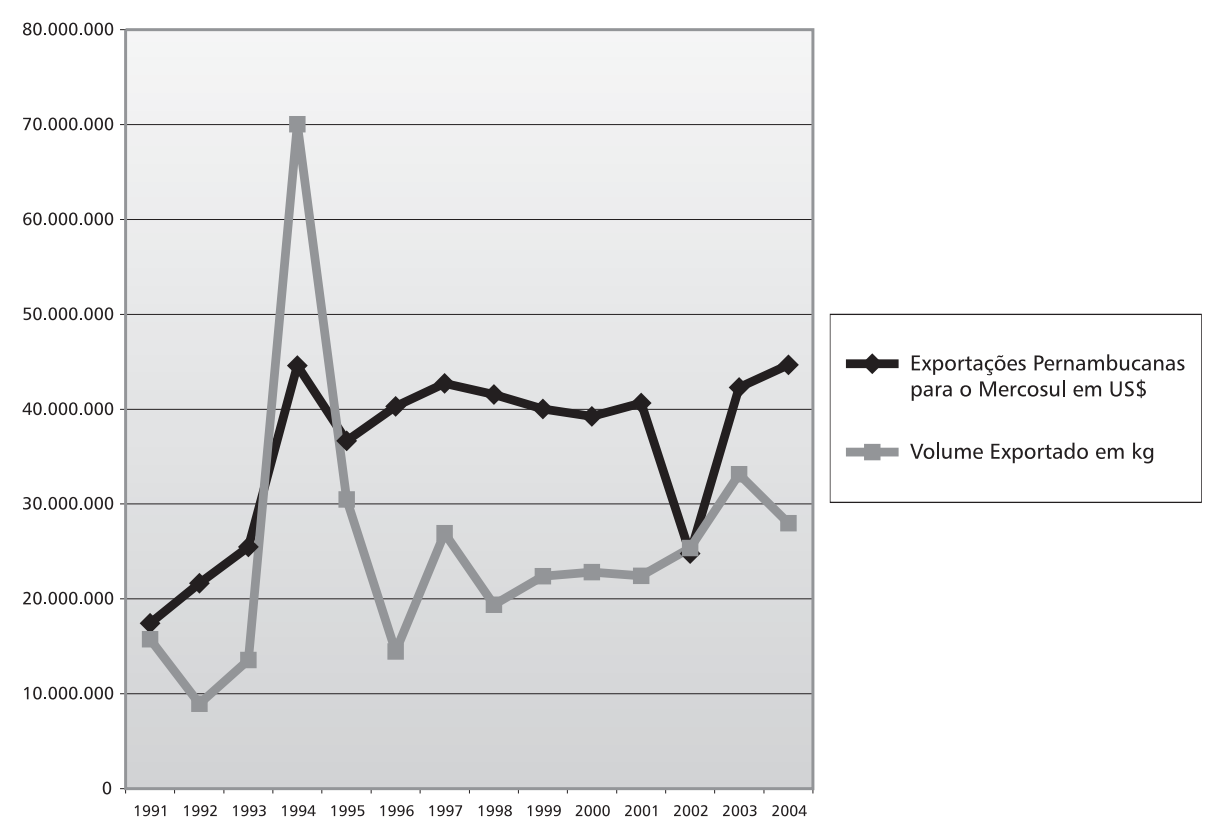

Tendo em vista as observações enumeradas no que toca os impactos do Mercosul na estrutura de exportações das unidades federativas de Pernambuco, Bahia, São Paulo e Rio Grande do Sul, pode-se assinalar que eles são diversificados e podem não ser benéficos para todos. Embora Pernambuco tenha melhorado a participação do Mercosul como destino de suas exportações e nos termos de intercâmbio, não se pode afirmar, ainda assim, que o Mercosul trouxe melhoras estruturais, pois embora exista uma ampliação da influência do processo de integração nesse estado, persiste nele uma estrutura produtiva com pouco dinamismo, quando comparada aos demais estados que compõe o centro econômico do país.

A partir da análise delineada e considerando as limitações da magnitude da amostra utilizada é possível inferir que não existe tendência que trace vantagens líquidas para as periferias em detrimento dos centros. Quando se observa a evolução das exportações e as possíveis melhoras dos termos de intercâmbio dos quatro estados com os membros integrantes do Mercosul, percebe-se que tanto Pernambuco, um estado localizado à periferia do estado brasileiro, como São Paulo, situado no centro, obtêm benefícios em relação a integração interestatal do cone sul da América meridional. De maneira simétrica, as possíveis desvantagens presentes no estado da Bahia também encontram ressonância no estado gaúcho. 


\section{Considerações finais}

O modelo centro-periferia e seu corolário forjado a partir de 1950 por uma equipe de pensadores tendo como mais eminente membro o economista argentino Raúl Prebisch, tem importância quando aplicado a estruturas infraestatais periféricas como os estados nordestinos, posto que oferece uma via para a saída de uma estagnação político econômica via integração regional. Notadamente sua versão hacia afuera, caracterizada por um protecionismo seletivo e restrito no tempo e no espaço. O Mercosul apresenta-se como rota alternativa para saída da dependência desses entes periféricos, possibilitando a ampliação do mercado consumidor, potencialidade de verticalização de cadeias produtivas e, em alguns casos, a ampliação das poupanças internas.

Contudo, apesar da possibilidade de benefícios emanados da integração, pouco foi de fato efetuado politicamente pelos estados pernambucano e baiano visando a ampliar essa proveitosa conexão. Ainda que existam casos pontuais de empenho para o alargamento desta relação, esses não são a regra, mas sim a exceção. Não há um reflexo sistemático de tipo institucional correspondente e de envergadura. $\mathrm{E}$ isso também ao nível das instituiçõos federais. A situação é mais dinâmica no que concerne às municipalidades de Recife e Salvador e, principalmente, Porto Alegre e São Paulo. Também o estado de São Paulo e, sobretudo, o do Rio Grande do Sul tendo se manifestado de forma mais ativa.

Todavia, constata-se, globalmente, um federalismo não cooperativo que se mostra danoso aos entes subnacionais. Ele é marcado por uma débil constituent diplomacy ${ }^{46}$ onde o ator central concentra o poder de concepção e implementação das políticas públicas de caráter internacional. Ela responde, essencialmente, aos interesses da matriz de desenvolvimento nacional, calcada em grande parte, nos interesses dos entes infra-estatais mais ricos - o centro - em detrimento dos menos favorecidos - a periferia. Além disso, o que se verifica é a hegemonia de uma integração negativa, mormente ancorada na supressão de obstáculos, sobre uma integração positiva, baseada em ações pró-ativas de criação de novos mecanismos institucionais ${ }^{47}$. Esses mecanismos atuariam enquanto catalizadores e balizadores do sistema de governança em

\footnotetext{
46 There is no settled terminology describing the international activities of constituent or 'subnational' governments. The term 'constituent diplomacy' is intended to be a neutral descriptor, one that avoids the implication that the activities of constituent governments are necessarily inferior, ancillary, or supplemental to the 'high politics' of nation-state diplomacy. Cf. KINCAID, John, "Constituent Diplomacy in Federal Politics and the Nationstate Conflict and Co-operation", in MICHELMANN, Hans J., SOLDATOS, Panayotis (eds.), Federalism and International Relations: The Role of Subnational Units, OUP, Oxford, 2001, p.74.

47 Cf. SCHARPF, Fritz W., Negative and Positive Integration in the Political Economy of European Welfare State. In: MARKS, Gary et al., Governance in the European Union, Sage, London, 1996.
} 
níveis múltiplos, sedimentando-o e perenizando-o. Buscaria-se nele uma relação ótima entre eficiência econômica e legitimidade política.

Recebido em 4 de abril de 2006 Aprovado em 20 de junho de 2006

\section{Referências bibliográficas}

BEZERRA, Eduardo. A transformação recente do perfil econômico do Ceará. Centro de Estudos Konrad Adenauer Stiftung, São Paulo, no 15, 209-216. 1998.

CASELLA, Paulo Borba. Mercosul: Mecanismos para a integração das regiōes. Centro de Estudos Konrad Adenauer Stiftung, São Paulo, no 15, 163-168. 1998.

Constituição do Estado de Pernambuco. Companhia Editora de Pernambuco, 1999.

Constituição da República Federativa do Brasil. Editora Saraiva, 1999.

CUNHA, Paulo G. de Araújo. O Brasil face aos mercados globais e ao regionalismo econômico: Uma perspectiva empresarial. Centro de Estudos Konrad Adenauer Stiftung, São Paulo, no 15 , 71-80. 1998.

DINIZ, Clélio Campolina. A dinâmica regional recente da economia brasileira e suas perspectivas. IPEA- texto para discussão, Brasília, no 375, 6/1995.

FISCHER, Berbhard. A Globalização e a competitividade dos blocos regionais: Uma visão comparativa. Centro de Estudos Konrad Adenauer Stiftung, São Paulo, no 15, 13-32. 1998.

GONÇALVES, Fernando Antônio. Algumas referências para a renovação da economia nordestina. Centro de Estudos Konrad Adenauer Stiftung, São Paulo, no 15, 205-208. 1998.

KINCAID, John. Constituent Diplomacy in Federal Politics and the Nation-state Conflict and Co-operation. In: MICHELMANN, Hans J., SOLDATOS, Panayotis (eds.), Federalism and International Relations: The Role of Subnational Units, OUP, Oxford, 2001, p.74.

KUME, Honório; PIANI, Guida. Efeitos do Mercosul: Uma análise diferencial-estrutural para o período 1990/95. Ipea- Texto para Discussão, Brasília, no 585, 8/1998.

LANGHAMMER, Rolf J., HIEMENZ, Ulrich, Regional Integration among Developing Countries: Opportunities, obstacles and options, JCB Mohr, Tübingen, 1990.

MANTEGA, Guido. A Economia Política Brasileira, Polis/Vozes, 1987, 4a .edição.

MARQUES, Renato. Instrumentos de competitividade intramercosul. Centro de Estudos Konrad Adenauer Stiftung, São Paulo, no 15, 155-162. 1998.

MATTOSO, Jorge. Relações internacionais e poder local: o caso de São Paulo. Política Externa, vol. 10, no 3. Universidade de São Paulo. (Gacint-USP)

MEDEIROS, Marcelo de A. et al, O Mercosul no limiar do século XXI, Editora Cortez, São Paulo, 2000.

, Marcelo de A. Prerrogativas Estatais e lógica distributiva. Lua Nova, São Paulo, n०58, 141-168. 2003.

The Institutionalization Process: Mercosur, Quo Vadis? Ten years of Mercosur. Cadernos del Cedla. Amsterdam, 37-48. 04/2002 
MENDES, Constantino Cronemberger. Efeitos do Mercosul no Brasil: Uma visão setorial e locacional do comércio, Ipea-Texto para Discussão, Brasília, no 510, 8/1997.

OLIVEIRA. Marcos A. Guedes de. MERCOSUL e Política. Editora LTR, 2001.

ORNELAS, Waldeck. Integração regional, soberania e política para as regiōes. Centro de Estudos Konrad Adenauer Stiftung, São Paulo, no 15, 145-154. 1998.

PREBISCH, Raúl. The Economic Development of Latin America and its principal problem. New York, ONU, 1950.

. America Latina: El Pensamiento de la Cepal, Chile, Editorial Universitaria, 1969.

RECENA, João J. Guimarães. O Nordeste do Brasil face ao MERCOSUL e à Globalização. Centro de Estudos Konrad Adenauer Stiftung, São Paulo, nº15, 163-168. 1998.

RIBEMBOIM, Jacques. Desenvolvimento setorial e meio ambiente: um enfoque na Região Nordeste do Brasil. Centro de Estudos Konrad Adenauer Stiftung, São Paulo, no 15, 183-190. 1998.

ROKKAN, Stein. State Formation, nation-building, and mass politics in Europe. Oxford Press, 1999.

SCHARPF, Fritz W., Negative and Positive Integration in the Political Economy of European Welfare State. In: MARKS, Gary et al., Governance in the European Union, Sage, London, 1996.

VIGEVANI, Tullo, RICUPERO, Bernardo. Comércio Internacional e Coalizões Sociais no MERCOSUL - perspectivas para o Brasil. São Paulo em PRESPECTIVA - MERCOSUL, Blocos Econômicos. Revista da SEADE, São Paulo, no. 1, 48 - 54.

VASCONCELOS, José Romeu de. Ceará, Pernambuco, Paraná e Rio Grande do Sul: Economia, finanças públicas e investimentos nos anos de 1986 a 1996. Ipea- Texto para Discussão, Brasília, nº626, 02/1999.

WANDERLEY, Livio A. O MERCOSUL e a Integração Mundial: Brasil, Nordeste e Bahia. Uniāo Européia MERCOSUL e Bahia: Novas relaçôes Centro-Periferia, Salvador, 91-101. 1998.

\section{Resumo}

Neste artigo procura-se associar os estudos teóricos relacionados à temática centroperiferia, multi-level governance, federalismo cooperativo e positive and negative integration à realidade empírica das unidades subnacionais no seio do Mercosul. São ainda efetuadas pesquisas de campo junto a atores políticos e representações de agentes econômicos a fim de privilegiar fontes primárias de informação e desta forma analisar comparativamente os impactos do Mercado Comum do Sul na economia política dos estados de Pernambuco, Bahia, São Paulo e Rio Grande do Sul, assim como em suas respectivas capitais.

\section{Abstract}

This article seeks to associate the theoretical devices related to the center-periphery theme, multi-level governance, federalism and positive/negative integration to the very reality of subnational unities within Mercosur. Some field inquiries with economical agents and political actors are subsequently considered in order to favor primary sources 
of information. Finally this text proposes to scrutinize the impact of the Southern Common Market on the political economy of Pernambuco, Bahia, São Paulo, Rio Grande do Sul and their respective capitals.

Palavras-chave: Mercosul; Unidades Subnacionais; Centro-Periferia; Federalismo; MultiLevel Governance; Constituent Diplomacy.

Key words: Mercosur; Subnational Unities; Center-Periphery; Federalism; Multi-Level Governance; Constituent Diplomacy. 